\title{
Afinal não era preciso amputar! Um caso clínico
}

Sara Nunes, ${ }^{*}$ Carla Gouveia**

\begin{abstract}
RESUMO
Introdução: Apresenta-se um relato de caso sobre doença arterial periférica em que o papel do médico de família é relevante em vários momentos: no controlo dos fatores de risco modificáveis, na coordenação da equipa de cuidados de saúde primários e na avaliação longitudinal do doente que, por sua vez, pode ser fundamental para o diagnóstico, prognóstico e seleção da opção terapêutica ao fornecer informação relevante aos cuidados de saúde secundários.

Descrição do caso: Mulher de 82 anos com dislipidemia, hipertensão e diabetes mellitus tipo 2, orientada e autónoma nas atividades de vida diária, iniciou úlceras arteriais de difícil cicatrização que infetaram. No contexto de sepsia foi detetada alteração do estado de consciência e assumido o diagnóstico de demência. Perante o quadro de insuficiência arterial grave bilateral dos membros inferiores foi proposta amputação. Esta foi recusada pela família e a doente teve alta para lar. Com o controlo da infeção recuperou o prévio estado de consciência. Foi reavaliada e proposta revascularização com sucesso. Houve cicatrização completa das úlceras com recuperação da autonomia e qualidade de vida prévia. Avaliando retrospetivamente o controlo dos fatores de risco vasculares detetam-se oportunidades não aproveitadas de otimização do mesmo. Os cuidados de enfermagem continuados durante vários meses não foram adequadamente intercalados por observações médicas, quer nos cuidados de saúde primários quer secundários. No diagnóstico de demência durante o estado de sepsia não foi considerada a informação do médico de família ou da família acerca do estado de consciência prévio da doente.

Comentário: Este caso mostra um bom desfecho (manutenção da autonomia e da qualidade de vida), salienta a importância do controlo dos fatores de risco de doença arterial periférica, da articulação entre profissionais nos cuidados de saúde (entre médicos e enfermeiros e entre cuidados de saúde primários e secundários) e das implicações que um adequado diagnóstico diferencial de alterações do estado de consciência tem para o prognóstico.
\end{abstract}

Palavras-chave: Isquemia; Qualidade de vida; Demência; Amputação; Caso clínico

\section{INTRODUÇÃO}

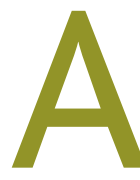
doença arterial periférica é uma patologia com fatores de risco como a diabetes, o tabagismo, a hipertensão, a dislipidemia, que são modificáveis. O médico de família tem um papel importante na vigilância e controlo destes fatores através do aconselhamento de medidas farmacológicas e não farmacológicas que incluem dieta, exercício físico, promoção da cessação tabágica e fármacos antidiabéticos, antidislipidémicos, anti-hipertensores e outros. ${ }^{1-3}$

Quando a evolução da doença arterial periférica chega a estadios mais avançados e a viabilidade do membro é colocada em causa existem opções terapêuticas

*Médica interna da formação específica em MGF na USF LoureSaudável

**Assistente de Medicina Geral e Familiar na USF LoureSaudável a ponderar, de acordo com alguns critérios. A amputação é aconselhada em situações de esperança de vida com qualidade limitada, quando exista sepsia, quando exista necrose significativa de partes de apoio do pé, contratura incorrigível, paresia da extremidade ou dor isquémica refratária. ${ }^{1}$ A revascularização é a opção em situações de falência da terapêutica médica para controlar a claudicação intermitente quando esta tem impacto na qualidade de vida e existe probabilidade de melhoria sintomática. ${ }^{1-4} \mathrm{O}$ médico de família, conhecendo não só a evolução dos sintomas como o impacto na qualidade de vida, pode ter um papel importante no fornecimento de informação relevante aos cuidados de saúde secundários para apoiar a decisão terapêutica mais adequada em cada caso.

A demência é uma patologia com grande impacto na qualidade de vida dos doentes e seus cuidadores e é 
motivo de ponderação quando as opções terapêuticas disponíveis implicam risco de vida ou de complicações graves. Situações de delirium podem ser confundidas com demência quando não são consideradas as circunstâncias, o tempo de instalação e evolução das alterações cognitivas. ${ }^{5}$ Está também ao alcance do médico de família, na sua prestação de cuidados longitudinal, prestar informação sobre estes aspetos.

O caso apresentado ilustra precisamente as potencialidades de atuação do médico de família nas vertentes atrás mencionadas.

É ainda discutida a articulação entre os elementos da equipa multiprofissional em cuidados de saúde primários, nomeadamente entre enfermeiros e médicos de família e como este caso teve impacto na reorganização de cuidados ao nível de uma Unidade de Saúde Familiar.

\section{DESCRIÇÃO DO CASO}

Mulher de 82 anos, em família unitária, com apoio dos filhos, residente em bairro urbano, previamente autónoma nas atividades da vida diária, tendo solicitado no ano anterior avaliação médica para efeitos de renovação da carta de condução, que fora aprovada por se encontrar física e cognitivamente apta.

A doente tinha antecedentes de hipertensão e dislipidemia desde os 51 anos de idade, não-medicada. Apresentava ainda insuficiência venosa dos membros inferiores desde a mesma altura. Aos 72 anos foi diagnosticada diabetes mellitus tipo 2 , tendo iniciado terapêutica antidiabética e estatina. Aos 76 anos iniciou seguimento pela primeira vez com a médica de família atual. Apresentava queixas de claudicação intermitente, pelo que foi otimizada a terapêutica anti-hipertensora, antidiabética e antidislipidémica e iniciada medicação antiagregante. Teve um episódio de úlcera do membro inferior direito que foi considerada pós-traumática. Teve boa cicatrização, em menos de um mês (venosa?, arterial?, mista?, pós-traumática sem componente vascular?).

Aos 81 anos, a doente desenvolveu úlcera de pequenas dimensões na região maleolar direita, mais uma vez justificada pela própria como pós-traumática. Iniciou pensos no centro de saúde e foi reobservada pela sua médica de família após 10 dias de tratamento por sinais de infeção, tendo sido reavaliada e medicada com tratamento eficaz. No entanto, manteve a realização de pensos com a enfermagem durante três meses, sem cicatrização da ferida e sem ter sido alertada a médica de família para ausência de resposta aos tratamentos. $\mathrm{Na}$ sequência desta ineficácia, a doente abandonou os cuidados de enfermagem no centro de saúde e passou a ser acompanhada num serviço de enfermagem particular. A falta da doente aos tratamentos não foi assinalada à sua médica de família nem se contactou a doente para averiguar o motivo da sua ausência.

Cinco meses mais tarde, a doente recorreu ao serviço de urgência por febre $\left(38,4^{\circ} \mathrm{C}\right)$ e prostração associadas a sinais de infeção de feridas de ambos os membros inferiores. Foi avaliada analiticamente e apresentava leucopenia 3,300/ $\mu \mathrm{L}$ e PCR 19,71mg/dL. Foi decidida alta, medicada com amoxicilina + ácido clavulânico $850 \mathrm{mg}+125 \mathrm{mg} 12 / 12 \mathrm{~h}$ durante oito dias. A creatinina nesta data era de $0,93 \mathrm{mg} / \mathrm{dL}$, a natrémia de $132 \mathrm{mg} / \mathrm{dL}$.

Quatro dias depois, a doente regressou ao serviço de urgência por ausência de melhoria e apresentar alteração do estado de consciência (Glasgow Coma Scale 14 em 15). Apresentava também uma temperatura de $39^{\circ} \mathrm{C}$, PA 99/50mmHg, mantendo PCR 19,80mg/dL e a creatinina tinha subido para $1,70 \mathrm{mg} / \mathrm{dL}$, tendo o sódio atingido $121 \mathrm{mg} / \mathrm{dL}$. Nesta data foi internada com o diagnóstico de sepsia e insuficiência renal aguda e foi, pela primeira vez, designada com o diagnóstico de demência. Iniciou antibioterapia com ceftriaxone e doxiciclina (desconhecem-se as doses usadas) com melhoria clínica e laboratorial.

Realizou-se doppler arterial dos membros inferiores que revelou doença arterial obliterativa multisegmentar com maior envolvimento no segmento femoro-popliteu e tíbio-peroneal bilateral. Foi então observada pela cirurgia vascular que se decidiu pela amputação como terapêutica. Esta proposta não foi aceite pela família que, apesar de ser dado conhecimento da evolução esperada, optou por transferi-la para um lar, onde manteve tratamento das feridas.

Não foi solicitada, pelos médicos do internamento, qualquer informação clínica à médica de família acerca do estado de consciência prévio da doente.

Dois meses depois foi reobservada em consulta de cirurgia vascular. Mantinha úlceras de ambos os membros inferiores: MID - necrose seca do calcanhar e do bordo externo do pé; MIE - ulceração extensa do dorso do pé com infeção e exposição tendinosa, necrose 


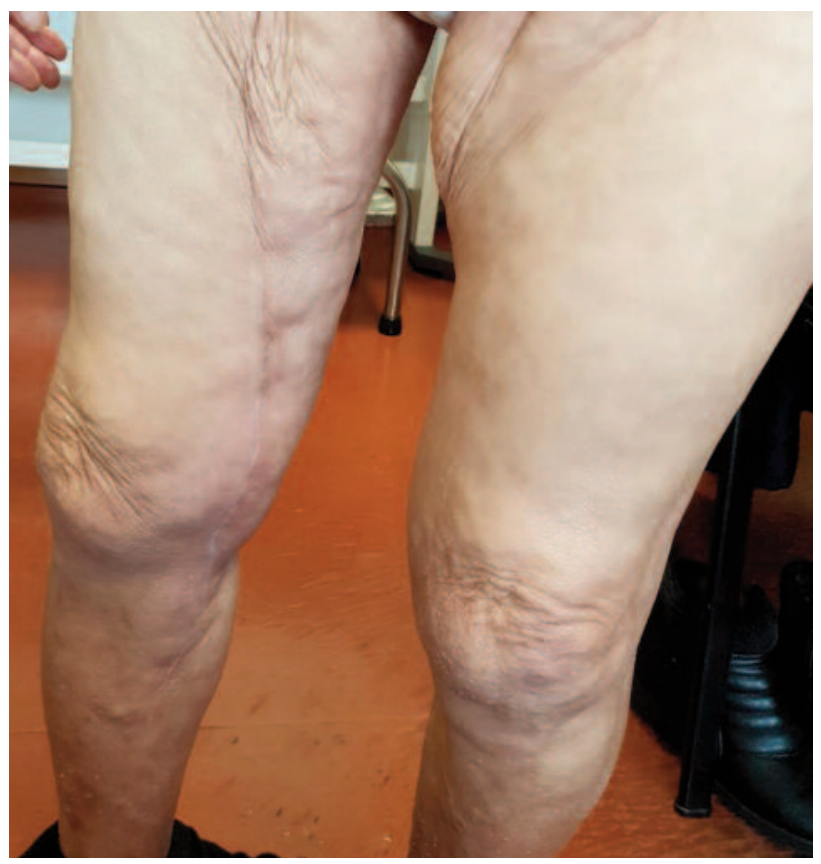

Figura 1. Feridas cicatrizadas (foto da doente).

seca do calcanhar. Desta vez foi proposta a estratégia de revascularização por bypass femoro-popliteu infragenicular com veia safena interna homolateral invertida bilateralmente, que foi aceite pela doente e família e realizada com um mês de intervalo entre as duas intervenções. Teve uma cicatrização completa das úlceras em três meses.

Neste momento, a doente encontra-se autónoma, com apoio de uma empregada doméstica, sem quaisquer lesões tróficas ou sintomas de doença arterial periférica. A recuperação do estado de consciência foi completa, não havendo sintomas ou sinais de demência atual.

A doente encontra-se muito contente com o resultado da cirurgia e com o bom aspeto das pernas (Figura 1). O filho reflete sobre o acontecido, dizendo que ainda bem que tomou aquela decisão, pois receava $o$ impacto psicológico adverso na mãe caso tivesse avançado para a amputação. Refere ainda que gostaria de ter tido acesso a mais informação prognóstica quando lhe foram apresentadas as hipóteses de tratamento.

\section{COMENTÁRIO}

Ao ter sido informada de um possível desfecho fatal, a família teve de decidir um dilema entre a sobrevivên-

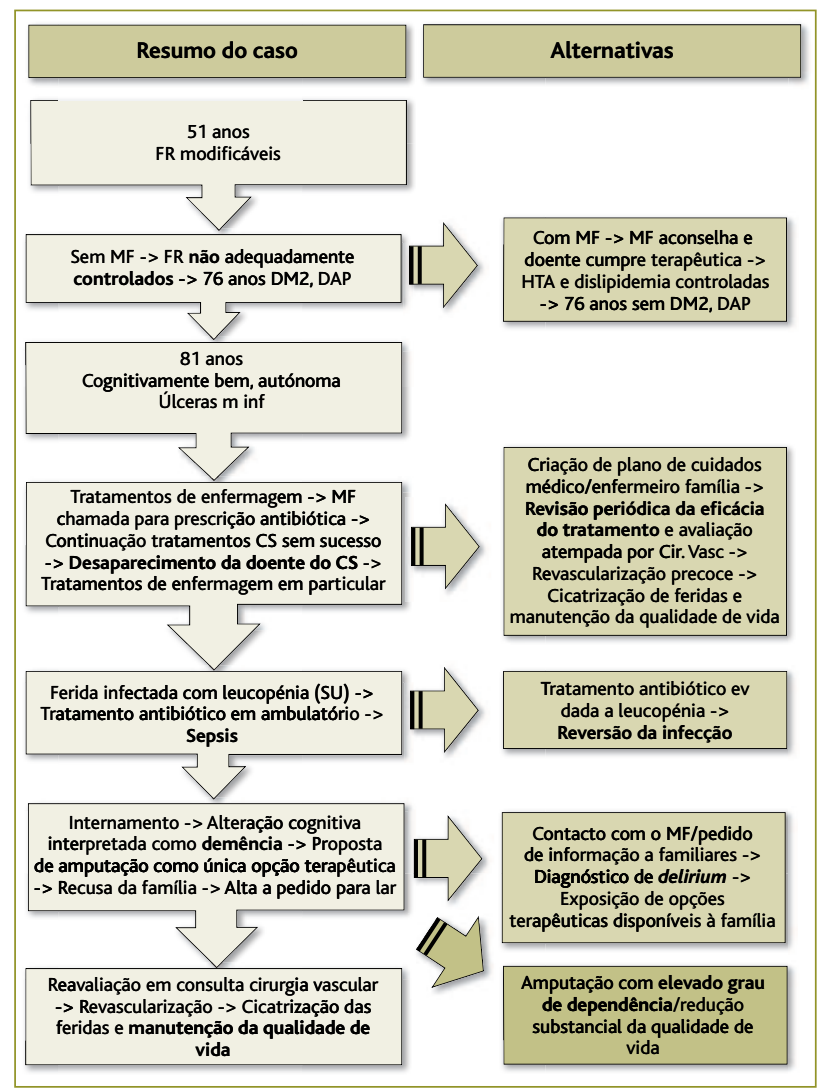

Figura 2. Esquema com resumo do caso clínico.

cia com amputação ou a redução da esperança de vida mantendo os membros inferiores. Esta decisão, que foi chave para o desfecho da história, foi descrita pelo filho como muito difícil de tomar.

Ao contrário do que seria de esperar com a amputação proposta de ambos os membros inferiores, com a revascularização foi possível preservar a autonomia da doente e a sua qualidade de vida.

$\mathrm{O}$ acompanhamento irregular dos fatores de risco de doença vascular apresentados pela doente pode justificar o agravamento da mesma e pode estar relacionado com o facto de não ter tido, durante muitos anos, um médico de família.

$\mathrm{O}$ facto de não ter sido comunicado à médica de família que estava a ocorrer um tratamento de enfermagem prolongado à ferida do membro inferior direito, nem posteriormente informado que $\mathrm{o}$ abandonou, pode ter atrasado a intervenção terapêutica da doença vascular e promovido o descontrolo dos fatores de risco. 
Seria de todo importante que os tratamentos de enfermagem fossem prioritariamente atribuídos à enfermeira de família (o que passou a acontecer após a reflexão sobre este caso), uma vez que esta tem uma interação mais próxima com o doente, os familiares e o respetivo médico de família. A reavaliação periódica pelo médico de doentes em tratamentos de enfermagem crónicos é também importante (foi também discutida e implementada na USF).

O diagnóstico de demência no internamento por sepsia foi precipitado, pois não considerou o diagnóstico diferencial de delirium de causa médica para o qual apontava este caso, nem o estado mental prévio da doente que podia ter sido avaliado junto da família ou da médica de família.

A comunicação entre médicos dos cuidados de saúde primários e secundários pode ser positiva, nestas e noutras situações, em prol do doente.

Caso o diagnóstico de demência estivesse presente em oposição ao de delirium, com uma doente sem autonomia, a decisão de amputar não seria tão contestável. No entanto, nesta circunstância, o prognóstico da doente seria afetado possivelmente de forma negativa se aquela tivesse sido a decisão tomada (Figura 2).

\section{REFERÊNCIAS BIBLIOGRÁFICAS}

1. Yang EH. Peripheral artery disease (PAD) guidelines [homepage]. Medscape; 2015 [cited 2018 Jan 2]. Available from: https://emedicine. medscape.com/article/2500033-overview

2. Hirsch AT, Haskal ZJ, Hertzer NR, Bakal CW, Creager MA, Halperin JL, et al. ACC/AHA 2005 Practice Guidelines for the management of patients with peripheral arterial disease (lower extremity, renal, mesenteric, and abdominal aortic): a collaborative report from the American Association for Vascular Surgery/Society for Vascular Surgery, Society for Cardiovascular Angiography and Interventions, Society for Vascular Medicine and Biology, Society of Interventional Radiology, and the ACC/AHA Task Force on Practice Guidelines (Writing Committee to Develop Guidelines for the Management of Patients With Peripheral Arterial Disease): endorsed by the American Association of Cardiovascular and Pulmonary Rehabilitation; National Heart, Lung, and Blood Institute; Society for Vascular Nursing; TransAtlantic Inter-Society Consensus; and Vascular Disease Foundation. Circulation. 2006;113(11): e463-654.

3. Society for Vascular Surgery Lower Extremity Guidelines Writing Group, Conte MS, Pomposelli FB, Clair DG, Geraghty PJ, McKinsey JF, et al. Society for Vascular Surgery practice guidelines for atherosclerotic occlusive disease of the lower extremities: management of asymptomatic disease and claudication. J Vasc Surg. 2015;61(3 Suppl):2S-41S.

4. Pangilinan Jr PH.Vascular diseases and rehabilitation [homepage]. Medscape.com; 2017 [cited 2018 Jan 2]. Available from: https://emedicine. medscape.com/article/312052-overview\#a8

5. Muché JA. Geriatric rehabilitation [homepage]. Medscape.com; 2017 [cited 2018 Jan 2]. Available from: https://emedicine.medscape.com/article/318521-overview\#a7

\section{CONFLITO DE INTERESSES}

Os autores declaram não ter quaisquer conflitos de interesse.

\section{ENDEREÇO PARA CORRESPONDÊNCIA}

Sara Nunes

E-mail: sara.m.o.nunes@gmail.com

http://orcid.org/0000-0002-7655-8356

Recebido em 11-08-2016

Aceite para publicação em 29-03-2018 


\section{ABSTRACT}

\section{AT THE END, AMPUTATION WAS NOT NEEDED! A CASE REPORT}

Introduction: We present a case report on peripheral arterial disease, in which we highlight the relevance of the role of the family doctor in various moments: management of modifiable risk factors, coordination of the primary care team, and longitudinal evaluation of the patient which, in turn, may be crucial for the diagnosis, prognosis and therapeutic choice, by providing relevant information to secondary care.

Case description: An 82- year old woman with dyslipidemia, hypertension and type 2 diabetes, oriented and independent in her daily life activities, developed difficult-to-heal arterial ulcers which became infected. In the context of sepsis, a change in the mental status was detected and the diagnosis of dementia was assumed. Amputation was proposed in the presence of extensive bilateral peripheral arterial insufficiency of the lower limbs. This option was refused by the family and the patient was discharged to a nursing home. Infection control resulted in the recovery of the previous mental status. The patient was reassessed and a successful revascularization was performed. The ulcers healed completely, with recovery of the previous levels of autonomy and quality of life. Evaluating retrospectively the management of vascular risk factors, missed optimization opportunities were detected. For several months, continued nursing care was not adequately coordinated with medical observations, neither in primary nor in secondary care. The diagnosis of dementia during sepsis did not take in account information from the patient's family, or of her family physician, on her previous mental status.

Comment: This case report shows a good ending (maintenance of autonomy and quality of life), stressing the importance of controlling the risk factors for peripheral arterial disease, of the articulation between various health care professionals (between doctors and nurses, and between doctors in primary and secondary care), and the implications of an adequate differential diagnosis of altered mental status in the patient's prognosis.

Keywords: Ischemia; Quality of life; Dementia; Amputation; Case report 